\title{
Contemporary Liberalism and Toleration $^{1}$
}

Liberalism, historically, is closely associated with increased toleration, so it is unsurprising that a variety of contemporary authors (Hampton, Kukathas, Barry, Ten) consider toleration to be "the substantive heart of liberalism" (Hampton 1989, 802). The precise role of toleration in liberalism, though, is unclear; different liberals have different views. In this essay, I will discuss three sorts of liberal theories and indicate how they approach questions of toleration, arguing that one of them supports toleration of more sorts of activities (including speech acts and lifestyles) than the others. While I think this is reason to favor that sort of theory, I will not defend that claim. Some reasonably think (and defend the view) that though toleration is of value, its limits should be drawn more narrowly.

In the first section, I introduce the conceptual nature of toleration, the nature of state toleration, and the two dominant ways philosophers might now be liberal theorists. With a nod to Rawls, I mark that distinction by talking of comprehensive doctrine liberalism and political liberalism (hereafter, CDL and PL). ${ }^{2}$ In section two, I consider the limits of toleration supported by the most prominent CDL on offer-Rawls's early view. I turn to PL in section three and then consider another view - what I think of as a thin CDL-in section four. I conclude, in section five, by briefly considering how the three positions would respond to the paradox of liberalism. The central claim defended throughout is that while PL might require toleration of more sorts of activities than Rawls's earlier CDL, the thin CDL discussed in section four requires more than either that CDL or PL. ${ }^{3}$

\footnotetext{
${ }^{1}$ Thanks to Andy Altman, Cleo Grimaldi, Christie Hartley, Shanna Slank, Bas Van Der Vossen, and Steve Wall, all of whom read previous versions of this paper and provided comments and criticisms that lead to serious improvements. Thanks also to the editors for inviting me to write this chapter.

${ }^{2}$ This distinction is now common, though different names are used for each of the views. PL is often called public reason liberalism, for reasons that will become apparent. CDL is sometimes called perfectionist liberalism, as some believe that endorsement of any political principle that does not emerge from public reason is tantamount to an endorsement of a conception of the good. (As will be clear, I believe this is a mistake.) I should also note that I use the acronyms CDL and PL (and, later, SL) for both liberalisms and liberals (views and advocates). When I use "CD" it can be either a liberal or nonliberal comprehensive doctrine.

${ }^{3}$ In a society with many people actively wanting to murder others, not tolerating that sort of activity would amount to not tolerating many acts. While I am inclined to think that a theory with fewer reasons for nontoleration is a society with more toleration, this will depend on the nature of those reasons.
} 


\section{Clearing the path: toleration, the state, and CDL vs. PL}

An act of toleration, I claim, is an agent's intentional and principled refraining from interfering with an opposed other (or their behavior, etc.), where the agent believes she has the power to interfere (Cohen 2004). ${ }^{4}$ If this definition is correct - and I think it is - it poses a problem for discussions of state toleration. Simply put, it is not clear that the state is the sort of entity that can act, let alone act in an intentional manner. ${ }^{5}$ Non-intentional non-interference, though, is not toleration. So how can the state tolerate?

I suggest that when we talk about a state tolerating, we are speaking elliptically about a state wherein all agents of the state act on, or are legally required to act on, a policy of toleration. Of course, citizens may tolerate regardless of their state's policies, which apply only to agents of the state. When citizens tolerate, we can say there is toleration within the state. When there is a state policy of toleration, we can say there is state toleration. A policy of toleration would require non-interference by agents of the state in specific sorts of activities - whether those agents oppose the activities or not. If the agents oppose the activities, they must tolerate. If they do not oppose the activity, they simply must not interfere with it (conceptually, they cannot tolerate the activity). So, a state policy of toleration requires that certain sorts of activities be either tolerated or at least not interfered with by agents of the state.

A state policy of toleration requires clear rules indicating what sorts of activities are to be tolerated (or not interfered with) and what sorts of activities warrant interference. Such policies require noninterference with activities for which there is opposition, whether that opposition is from agents of the state or other citizens. For example, many in the U.S. oppose atheism and any statements of atheism. Whether or not current agents of the state oppose such statements, a state policy of toleration is possible. Similarly, there is likely opposition to the religious activities of any given religion practiced in the U.S. - and again, whether or not current agents of the state oppose such activity, a state policy of toleration is possible. Policies that require non-

\footnotetext{
${ }^{4}$ There I also argue that the act must take place in a "situation of diversity."

${ }^{5}$ Margaret Gilbert, Michael Bratman, and others argue that groups can have collective intentions. Even if those views make sense of some groups having intentions, making the case that states can have intentions of the same sort you and I have is more difficult. I assume states do not have intentions in anything but an attenuated sense-agents of the state have intentions and they may want it to be as if the state has particular intentions - but my central claim does not depend on this.
} 
interference where there is no opposition, on the other hand, would not be considered policies of toleration.

One final — but large — piece of path clearing is needed: explaining comprehensive doctrine liberalism (CDL) and political liberalism (PL), with an eye toward exposing the different ways they endorse toleration. A comprehensive doctrine "includes conceptions of what is of value in human life, and ideals of personal character, as well as ideals of friendship and of familial and associational relationships, and much else that is to inform our conduct, and in the limit to our life as a whole" (Rawls 1993, 13). These ideals "are to inform much of our nonpolitical conduct (in the limit our life as a whole)" (ibid, 175). (The "in the limit" talk makes clear that doctrines can be more or less comprehensive.) A CDL is any liberalism that is essentially tied to (or is itself) a comprehensive doctrine; different CDLs are tied to different comprehensive doctrines. Some Kantians, with a rather robust view about moral autonomy, are CDLs. So too, though, are some utilitarians and natural law theorists (etc.). These CDLs could be in debate with one another to determine the best defense of liberalism (and perhaps the best form thereof). PL is meant to rise above such debate so long as the CDLs in question are reasonable.

Undeniably, there are plural comprehensive doctrines in contemporary liberal societies. The core political principles that all reasonable CDs accept are, collectively, the subject of an overlapping consensus and would be the free-standing principles of a PL society, not dependent on any particular CD or its metaphysical claims. "Person A may support political liberalism as the implication of her utilitarianism; person B may support it as the implication of his religious faith; person $\mathrm{C}$ may support it as the core of her less tightly organized hodgepodge of other moral commitments" (Mills 2000, 191).

Skeptical of getting agreement, PLs are unwilling to base principles of justice (or constitutional essentials) on metaphysical assumptions that reasonable others might reject. This constraint allows them to concentrate their concerns on the political arena. Refusal to rely upon controversial metaphysical claims is, thus, only one characteristic of political liberalism. A second is its limited domain. CDLs have commitments that affect aspects of their lives beyond the political and that they may believe should limit what others should be allowed to do. Millian 
utilitarians, for example, might advocate liberalism because it creates the most happiness. Such a CDL would also be committed to creating the most happiness possible, no matter where or when. An autonomist CDL (discussed in the next section), by contrast, insists individuals have moral autonomy throughout their lives. Political liberals, by contrast to both, make no such claims; in their view, "a political conception of justice should apply only to the basic structure of society" (Davis and Neufeld, 50). Theoretically, individual PLs may endorse moral views and policies for all arenas of their own lives, simply insisting that this fact is irrelevant to the state. Though they thus might endorse a CD, they also insist that the only part of that CD that would matter for others (who do not endorse it) are the principles that are the subject of the overlapping consensus (which they also endorse). As one Rawlsian puts it, “[p]olitical liberalism distinguishes comprehensive doctrines, which include moral ideas that guide people in all aspects of their lives, from political conceptions, which comprise moral ideas and values expressed in political judgments" (J. Cohen 2009, 12).

Once metaphysical commitments are rejected as grounding political principles, what is the political liberal left with? PLs insist that only "public reasons" can be used in political discourse. ${ }^{6}$ Public reasons are those that it would be reasonable for any citizen to assent to. ${ }^{7}$ They thus exclude all purely religious claims - since there will be citizens that would reasonably disagree with any such claim. They exclude, in fact, all metaphysical claims since these might be controversial — which here means "subject to rejection by those committed to some reasonable comprehensive doctrine." Different individuals may accept public reasons for different reasons, each finding grounding support for them in their own CD. The policies of toleration the PL will espouse are thus those that are justified by public reasons. CDLs, by contrast, willingly endorse some metaphysical claims (which claims depends on their CD) and these claims ground their political principles, including principles of toleration. Those endorsing such a view do not claim their metaphysical claims are uncontroversial. They simply insist on—and defend—-their

\footnotetext{
${ }^{6}$ In 1999. Rawls backs away from this, allowing that such claims can be used in public discourse in non-ideal circumstances if they are supplemented by public reasons "in due course" (584 and 591-594).

${ }^{7}$ On a different sort of PL view, what matters is that all reasonable persons (and their CDs) accept the basic political principles of the society, though they accept those principles for their own (different) reasons. Rawls sometimes writes as if this is his view; talk of an "overlapping consensus" suggests it. See Wenar, 53-54. For clear statements differentiating the two sorts of views, see D’Agostino, 30 and Nagel, 218.
} 
correctness. It may be an insistence on the value of autonomy, the value of happiness produced, or something else that grounds the relevant liberalism. (These do not exhaust the possibilities.) ${ }^{8}$

On the face of it, advocates of PL seem likely to tolerate more sorts of activities than advocates of CDL. PLs, after all, will not try to defend the criminalization (or other legal interference) of any sort of activity without reasons acceptable to adherents of all existing reasonable comprehensive doctrines, including those they dislike or disapprove of. ${ }^{9}$ By contrast, a CDL could argue for or against the criminalization of some activity based on reasons not acceptable to adherents of competing reasonable comprehensive doctrines. A utilitarian CDL, for example, might argue for the legal permissibility of abortion in cases of type $\mathrm{X}$ with empirical information that strongly supports the view that allowing abortion in such cases promotes overall utility. ${ }^{10}$ It would not be reasonable, however, to expect a Roman Catholic (whether endorsing a CDL or not) to assent to reasons justifying a law permitting abortion. ${ }^{11}$ A defender of either CD would thus support policies on the basis of reasons that are reasonably opposed by the other, seeming to demonstrate intolerance toward the other. PLs, by contrast, claim we should "accept or tolerate people's affirming and acting on the particular beliefs [e.g., those from their particular CDs] that provide them with reasons" and argue that "[p]ersons and principles of justice are unreasonable insofar as they do not tolerate or accept that false beliefs can provide others with good reasons for acting - good reasons insofar as these reasons fit with their rational plan of life and reasonable comprehensive views" (Freeman, 228). They would thus not support a policy justified by reasons specific to the Roman Catholic or utilitarian CDs. ${ }^{12}$ It thus seems they would tolerate more sorts of activities than either CD.

\footnotetext{
${ }^{8}$ We cannot survey all CDLs here. Nor can we survey all PLs. It should be remembered, though, that the overlapping consensus that emerges in a society would depend on the extant CDs within it. At the theoretical level, though, how best to understand the process by which an overlapping consensus is derived is a matter for debateWilliam Galston, Jerry Gaus, Jurgen Habermas, and Charles Larmore offer important and interesting alternatives. (There is also disagreement about how best to interpret Rawls's PL.)

${ }^{9}$ More precisely, they (or Rawlsian PLs, anyway) won't defend principles of justice and constitutional essentials that would support such criminalization (etc.) without reasons acceptable to all reasonable CDs.

${ }^{10}$ I am not claiming there are cases of type $\mathrm{X}$.

${ }^{11}$ See Freeman, 236.

${ }^{12}$ Its not clear what this means for the abortion case specified. If there are no public reasons for laws against abortion, the PL would be unable to endorse such laws. But if there are no public reasons for laws permitting abortion, the PL would be unable to endorse those laws. This is an old problem in new guise: if law allows abortion, the Roman Catholic's view is rejected for purposes of law; if the law outlaws abortion, the utilitarian's view is.
} 
With the CDL/PL distinction now clear, I turn to examining how each treats toleration.

\section{One Comprehensive Liberalism's Limits of Toleration (Rawls' early view)}

Every political philosopher today recognizes the importance of John Rawls's Theory of Justice.

With it, Rawls single-handedly reinvigorated political philosophy in the English-speaking world and introduced new terms and concepts into our discourse. Part of his brilliance was reinvigorating the idea of hypothetical consent. Classical contract theorists started with a state of nature, asking how people might exit it, consenting to civil society. Rawls considered the state of nature a mere example of an original position and offered, in its place, his veil of ignorancea heuristic device wherein we seek to determine the principles of justice we would agree to if we did not know who we were.

The veil of ignorance is an impressive device for determining what we should each agree to (or would agree to if we donned the veil). Critics argued, though, that the ability to think of oneself as the sort of being present behind the veil requires thinking of oneself as separate from all of one's ends, including commitments to others, desires, etc. That, it was (and often still is) thought, is impossible, requiring radical independence or autonomy of the self. It was also claimed that no agreement made behind the veil could have normative force for us since we are not the agents behind the veil. The important point here is that Rawls seems to have a contentious view of the individual grounding his liberalism, which, it is often thought, thereby promotes moral autonomy.

Behind the veil, Rawls argues, we would endorse two principles of justice. The first - the liberty principle - requires that each of us have the most extensive set of basic liberties compatible with everyone else having the same. The second requires that social or economic inequalities are just only if they are to the advantage of the least well off and all have fair equality of opportunity to attain the social (or political or economic) positions that correspond to the inequalities (the difference principle and equal opportunity principle). ${ }^{13}$ Importantly, on Rawls's view, "by acting from these principles persons are acting autonomously; they are acting from principles that they

\footnotetext{
${ }^{13}$ See, for example, Rawls 1971, 302.
} 
would acknowledge under conditions that best express their nature as free and equal rational beings" $(1971,515)$. Hence, on this view moral autonomy is required — as it allows us to determine the principles of justice.

With some understanding of Rawls's 1971 view in place, we can ask the simple question: what does it require a just state tolerate? Putting the point simply, $\mathrm{X}$ is to be tolerated if it is it in accord with the two principles of justice that emerge from the original position. Some clarification. A state is just, on this view, if it is in accord with the two principles of justice and so long as the state is just, its laws determine what must be tolerated. ${ }^{14}$ This means the state must not have a law requiring interference with $\mathrm{X}$ if that law would make the state fail to be in accord with the two principles.

Consider some examples. A society can be just in Rawls's scheme if its laws tolerate medical doctors earning substantially more than others, so long as this inequality makes it such that there will be more doctors than there would otherwise be so that even the least well off are more likely to receive medical attention when needed than they would otherwise be (and assuming the first principle is satisfied). Similarly, a society can be just in Rawls's scheme if it tolerates homosexual marriage, marijuana use, and masturbation. A society cannot be just in Rawls's scheme if it tolerates a religious organization that forbids women from running for government office and requires they be subservient to men, allowing them fewer liberties. Similarly, a society cannot be just in Rawls's scheme if it tolerates a political order that grants economic rights to some and not others, nor if it tolerates an economic order that allows some to have political liberty but not others.

Imagine a religious organization develops, centered on the teachings of a previously unheard of wise woman. Her followers become faithful as adults - they were not raised in the religion, which did not exist before. Imagine, further, that her followers are (or were) all intelligent, freethinking, and autonomous and that they all intentionally and with full knowledge of the

\footnotetext{
${ }^{14}$ In addition to the choice of the two principles, Rawls discusses a "constitutional convention," a "legislative stage," and a stage wherein rules derived in the prior stages are applied and followed (1971, 195-201). For simplicity's sake, I will assume the two principles and the constitutional essentials determine what is tolerated.
} 
expected consequences, give their informed consent to join the new organization. Imagine, finally, that these initiates agree to abide by the wise woman's teachings and to raise their children using techniques we might call "brain-washing" to guarantee they will be faithful to the wise woman's teachings when they become adults. The initiates would essentially be voluntarily and autonomously sacrificing their own autonomy and political liberties and binding their children to the same. Rawls's CDL would not tolerate such behavior as it treats autonomy as a value such that the promotion of non-autonomy cannot be tolerated. ${ }^{15}$ Indeed, we might appropriately call Rawls's CDL autonomist. ${ }^{16}$

Now that we have some understanding of what Rawls's 1971 CDL would and would not tolerate, we move on to consider PL. Later, in Section IV, I discuss a third position-what I think of as a thin CDL. First, though, take stock of a key factor: CDLs have independent commitments that dictate their approach to toleration and may have principles grounded in those commitments indicating when the limits of toleration have been broached. A PL is different.

\section{Political Liberalism's Limits of Toleration}

Despite offering (in his 1971) what some think of as the best defense of liberalism in over a century, Rawls came to realize his view might face opposition as a CDL. What it needed, he thought, was to be supplemented with an account of what would make a state legitimate and stable. The result is his PL, a theory about how core political principles can be anchored in an overlapping consensus endorsed by all reasonable CDs. By virtue of that wide-ranging endorsement (read: consent), the PL society would not only be stable but also legitimate. ${ }^{17}$

\footnotetext{
${ }^{15}$ We can talk of a contrast of autonomy and toleration: if toleration is the preeminent value, autonomy and nonautonomy can both be tolerated; if autonomy is, non-autonomy cannot (cf. Tan, 51)

${ }^{16}$ In his 1993, Rawls attributes this view to Kant and Mill: "the ethical values of autonomy and individuality, which may apply to the whole of life, both social and individual, as expressed by the comprehensive liberalisms of Kant and Mill" (Rawls 1993, 78). The attribution to Mill is mistaken since "Mill was almost obsessively concerned ... with keeping the state out of any attempt to mould character" (Barry, 119).

${ }^{17}$ See Rawls 1993, 29-35
} 
Remarkably, Rawls believes PL results in an overlapping consensus on the principles of justice endorsed in his earlier view. ${ }^{18}$ Given that the overlapping consensus is determined by the existing reasonable CDs and that these vary from society to society (and can change over time), this seems highly unlikely. If it were right, a PL society would presumably tolerate the same things as Rawls's CDL. Assuming this is not the case, the general question for PL is what sort of principles all who adhere to reasonable CDs would accept. For the PL, X should be tolerated if it is it in accord with public reason. Some clarification, once again. A state is legitimate, on this view, if justified by public reason. ${ }^{19}$ So long as the state is legitimate, its laws determine what must be tolerated. This means the state must not have a law requiring interference with $\mathrm{X}$ if that law would make the state fail to be in accord with public reason. As standardly read, this requires that individuals have political autonomy but not moral (ethical) autonomy (1993, 77ff).

The idea behind the political autonomy requirement is straight-forward: citizens must have the protected right to vote and perform other behaviors associated with living in a liberal democratic regime, ${ }^{20}$ but in their private lives, they may, to put the point bluntly, be led by others. So, for example, those in the religious group discussed above (in the penultimate paragraph of the last section) would be free to act as indicated so long as the members retained their political rights. This presumably means they must be allowed to vote, to leave the religious group's compound, etc. $^{21}$ If they choose, though, to accept subservient roles on that compound, the PL state would tolerate it. This allows that both those whose reasonable CDs value (moral) autonomy and those whose reasonable CDs do not (or do not value it for some, usually women) can continue to live according to their CDs, with all being politically autonomous. PL "affirms political autonomy for all but leaves the weight of ethical autonomy to be decided by citizens severally in light of their comprehensive doctrines" (Rawls 1993, 78). In PL, then, toleration's value seems weightier than that of moral autonomy. The laws of a PL state may tolerate groups that have members with less freedom within the group than other members - so long as they all have political autonomy (can participate as autonomous citizens with the state), they do not have to

\footnotetext{
${ }^{18}$ As an exception, he claims justice as fairness is but one of "a family" of PL views at 1999, 581.

${ }^{19}$ More clearly, the core political principles must be justified by public reason and the laws must be in accord with the core principles. For simplicity's sake, I will assume public reason determines what is to be tolerated.

${ }^{20}$ See Rawls 1999, 581.

${ }^{21}$ See Rawls 1999, 597.
} 
have full participation rights in the running of their own households, churches, or cultural groups. (PLs might oppose how such groups are organized even if they do not think the state should interfere.) Again, PL seems capable of tolerating more than CDL. ${ }^{22}$

Pluralism of CDs is an empirical fact of contemporary society-indeed, any society with freedom of conscience. This is due to what Rawls calls "the burdens of judgment.",23 Reasonable persons, on his view, recognize these burdens and how they make pluralism of CDs inevitable and thus support toleration and public reason $(1993,58-59)$. All of this should be accepted. What must also be recognized, though, is that on this view, anyone insisting that their $\mathrm{CD}$ is the single true religious or philosophical CD and who cannot understand how others can reasonably disagree are, on this account, unreasonable (ibid, 60) and by virtue of that, excluded from the public reason bargaining table, as it were (cf. Tan, 54). Of course, the PL state may include liberties adherents of unreasonable CDs reject (and may reject some they want). This means that any promise of PL to accommodate the real diversity modern societies contain is doomed from the start. The real diversity of contemporary societies includes unreasonable CDs and their views are not included in the crafting of public reasons. "We are not required ... to take seriously the political views of unreasonable persons" (Friedman, 17). For them, "the recommendation of political liberalism is to craft a limited exchange that avoids a confrontation of the beliefs that both illiberal and reasonable people tend to think are most important: the comprehensive beliefs" (Scalet, 96). In so doing, PL fails to show them respect as practical reasoners. To show them such respect requires believing it worth helping them to see the truth (or at least the good argument) behind the core liberal principles - and so believing they can come to see it. This requires willingly confronting their CDs in an open and honest attempt to convince them of liberal values (ibid, 102-104) — and so openness to being convinced one is wrong oneself. Holders of unreasonable doctrines are instead "treated like the bearers of a pestilence ... excluded from the legitimation pool, that collection of citizens whose consent to the political system confirms its legitimacy" (Friedman, 22). PL thus "wins consent [and

\footnotetext{
${ }^{22}$ This seems to me a false promise of political liberalism - one that cannot be fulfilled. See Wenar for further defense than I offer in what follows. See Gaus for perhaps the most impressive attempt to date to defend a version of PL (with many differences from Rawls's) that may avoid this problem. See especially his 359-368.

${ }^{23}$ These include, but are not limited to: the facts that evidence is "conflicting and complex," that people disagree about the weight any given consideration should have, that concepts are vague, and that our upbringing affects how we assess evidence. (See 1993, 56-57.)
} 
legitimacy] only by excluding from the outset those very persons whose illiberal convictions would lead them to reject the system" (ibid, 31). Indeed, "the main aim of political liberalism is to address those who are committed to constructing terms of social cooperation that respect all persons as free and equal citizens" (Hartley and Watson, 515). Those not so committed need not be consulted. $^{24}$

Two points should be clear here: (1) PL fails to respect adherents of CDs deemed unreasonable and (2) given that lack of respect, PLs are quite happy to allow the existing diversity of CDs to evolve into a "reasonable pluralism" wherein all remaining CDs are reasonable. That is, PLs are comfortable with policies a consequence of which is the ending of unreasonable comprehensive doctrines. These policies may tolerate the unreasonable CDs in so far as they do not overtly call for their elimination, but such policies might have spillover effects destructive to those CDs. ${ }^{25}$ This is not, on its own, a criticism of PL-certainly not a liberal criticism of PL. All liberals, after all, will have to limit the role of illiberal practices. Nonetheless, the second point is, on its own, worth attention as liberals_ - perhaps especially PLs — at least play lip service to preferring to help diverse social (religious, moral, etc.) groups prosper.

A question should now loom for the PL: might the spillover affects destructive to unreasonable CDs also be destructive of reasonable CDs, causing them a loss of adherents? Though a negative answer is surely implausible here, it may well be that reasonable CDs would also gain members in the process. After all, actual world well-educated people sometimes become more religious rather than less. It is an empirical question: would reasonable CDs survive in a society committed to basic political principles that are the subject of an overlapping consensus? More importantly, would adherents of reasonable CDs believe they would? If not, it would be

\footnotetext{
${ }^{24}$ PLs will say that holders of unreasonable doctrines are to be respected in a PL society-insisting, for example, that they have the rights and liberties accorded everyone else. The disrespect indicated above is, we can say, at a different level. CDs deemed unreasonable are given no truck in PL theorizing about what the state should be and those adhering to such CDs are thought to somehow be deficient in adhering to them.

${ }^{25}$ Perhaps there will be policies requiring enough education so that all could be good citizens-for example, giving them the ability to critically reason (so as to vote well). This, combined with being taught they have state protected civil rights (even against their own families and CD-groups), could lead them to exit their CD: upon critically analyzing their $\mathrm{CD}$, they may find it lacking; given knowledge of their rights, they may exercise them. There is much written about this. See Gutmann for an excellent defense of the claim here and Davis and Neufeld for some response (not meant as a full defense of PL).
} 
surprising if they endorsed the principles about which there is hoped for consensus. ${ }^{26}$ Two possibilities follow from this: either representatives of reasonable CDs will believe their CDs would survive in a PL state or a PL state would not obtain (since no one would endorse reasons supportive of principles that lead to their CD's failure). Put simply, either the subject of the overlapping consensus is consistent with a stable society of competing and diverse CDs or its not; if not, a PL state cannot obtain. (There would be a diversity of CDs, but not in a PL state.)

Ignoring the possibility that a PL state might not be possible, it is important that the sort of toleration required by PL can leave CD groups eviscerated over the long-term. This may not be an embarrassment to the PL. However, I would think our chief concern would be that people live well (what other legitimate concern can there be for the state?) and I think people can live well in groups committed to CDs that are not liberal. Indeed, I suspect some people cannot live well without such a group as I will discuss in $\S I V$. I thus think it important that such groups be tolerated, where this means not merely that there is no intent to destroy such groups, but that there be no unnecessary intentional action a known byproduct of which is their destruction. PL does not seem to offer this, despite claims of inclusiveness. Its commitment to political autonomy and rejection of the unreasonable as fit to participate in determining principles of justice prohibits toleration of more ways of life than PLs are apt to advertise. Whether it allows toleration of more ways of life than a CDL depends on the sort of CDL considered-likely more than autonomist CDL, but less than others.

Our conclusion about PL is unsurprising. Though it wishes to shed commitment to controversial claims, after all, PL is a form of liberalism, and liberalism itself may be controversial. More to the point, it would seem that no matter what we do to make liberalism acceptable to groups not ordinarily part of its reach, liberalism must remain committed to the value of the individual. One PL recognizes this explicitly:

Liberalism, formulated as a strictly political doctrine ... forms a freestanding conception in regard to comprehensive moral visions of the good life, but it cannot coherently claim to be freestanding with respect to morality altogether. In particular, we would be wrong

\footnotetext{
${ }^{26}$ Even parties behind a veil of ignorance would, I think, worry about the survivability of reasonable CDs since they might be committed to one (see Rawls 1993, 22-28 and 304-310).
} 
to suppose that the moral principle of respect for persons has the political significance it does because reasonable people share a commitment to it. On the contrary, the idea of respect is what directs us to seek the principles of our political life in the area of reasonable agreement. Respect for persons lies at the heart of political liberalism, not because looking for common ground we find it there, but because it is what impels us to look for common ground at all (Larmore, 608, emphasis added). ${ }^{27}$

For liberalism to be liberalism, it cannot be "political all the way down." It must accept that respect for persons matters morally.

Just what respect requires remains a question. I suggested above that it requires being willing to engage in honest dialogue seeking to persuade. Given concern to broaden the appeal of liberalism, the PL suggests we can make do with respect for persons as citizens (with political autonomy). As it turns out, this may not be the way of broadest appeal.

Let's take stock, briefly. CDL has independently defended policies of toleration. By contrast, the PL requires toleration of whatever the overlapping consensus demand be tolerated. A likely exception to this is a principle of respect for persons. We can now ask whether there might be a thinner moral principle — which would have broader appeal — to ground liberalism.

\section{A Thin Comprehensive Liberalism's Limits of Toleration}

According to Larmore, there must be a moral grounding to any defensible political theory. A moral grounding that is likely to receive universal assent, or as close to universal as possible, is desirable. Hence the move many make to PL-the hope is that putting metaphysical claims (about personhood, e.g.) to the side will result in a political view that all can accept. It would plausibly get more acceptance since more people believe reasonable persons must be respected than believe all individuals must be morally autonomous. PL is thus supposedly thinner than

\footnotetext{
${ }^{27}$ Ultimately, Larmore tells us, it is Rawls's liberal principle of legitimacy that does the moral work "as it expresses in effect the idea of respect for persons" (Larmore, 610).
} 
autonomist CDL, insisting only on political, rather than the more robust moral, autonomy. ${ }^{28} \mathrm{PL}$ is thereby meant to be more inclusive - the thinner the requirement, the more inclusive the view. But there are other forms of CDL—something oddly ignored in much of the literature about CDL and PL.

Autonomist liberals take autonomy (often Kantian) to be the core liberal value. Other CDLs are also perfectionist in the sense that they believe the right core values are those that lead individuals to the good. Autonomist liberals think autonomy is required for human perfection; other perfectionist CDLs flesh out perfection differently. A non-perfectionist CDL is also possible. This sort of CDL endorses a value, but not a value meant to lead individuals to the good even if it (intentionally or not) enables people to lead good lives. This is a liberalism that treats toleration as the single correct state policy, ${ }^{29}$ not because of an overlapping consensus in favor of doing so, but because of a grounding value. In this section I discuss such a thin CDL that insists on neither moral nor political autonomy for all, showing how it may fare better than PL in terms of broadening the inclusiveness of liberalism.

Here is a moral principle: suffering is bad. This seems analytically true but also has normative bite since, prima facie, badness (again, analytically) should be avoided. It suggests states should be concerned to limit suffering. Ending suffering, of course, would be an overly burdensome requirement. There is suffering throughout the world, amongst humans and non-humans, and no state could hope to end it, even within its borders. Moreover, some sorts of suffering, while morally important, are obviously not political matters. The suffering of a broken heart, for example. The general concern is that people be able to live well—without suffering. The narrower, political, concern is that people not be prevented from living well-and made to suffer - by other agents. The state ought to work, then, to prevent the intentional infliction of suffering. This suggests a particular account of liberalism that takes freedom from harm to be the core political value, requiring that toleration's proper normative limit is the causing of harm

\footnotetext{
${ }^{28}$ We can frame this differently, in terms more amenable to Larmore's argument. PL ultimately relies on respect for persons and this may well be a thinner requirement than moral autonomy. Whether it is as thin as political autonomy is meant to be, I leave to the side.

${ }^{29}$ There are affinities between this approach and Dworkin's neutralist approach, which is another form of nonperfectionism.
} 
(and so suffering).

According to this CDL, all behaviors are to be equally tolerated by the state so long as no harm is done to others. (The state thus ought to work to prevent harm-and perhaps punish harm-doers or otherwise work to bring about rectification of harms done.) John Stuart Mill wrote: "The sole end for which mankind are warranted, individually or collectively, in interfering with the liberty of action of any of their number is self-protection ... the only purpose for which power can be rightfully exercised over any member of a civilized community, against his will, is to prevent harm to others" $(1859,9)$. This is the guiding idea of this CDL. A state committed to it does not seek to make people morally autonomous but leaves them to live as they wish. ${ }^{30}$ Put differently, such a state leaves people to live according to their conscience, ${ }^{31}$ whether their consciences are rationally and autonomously developed or the result of socialization and indoctrination. This CDL, in other words, requires respect for persons as they are-which is to say it requires toleration of people acting on their own actual wishes. ${ }^{32}$ The limit, again, is behavior that is harmful—i.e., we need not tolerate behavior that wrongfully sets back the interests of others (see Feinberg 1984, 36). Joey's stabbing innocent Rachel is a harm; a tree branch on my property falling on my head is not — though it is a hurt or setback of interests. In this CDL, P should be tolerated unless he causes or is likely to cause harm in this sense. On this view, laws are just if they are in accord with this requirement. This means the state must not have a law requiring interference except to prevent or rectify harm.

\footnotetext{
${ }^{30}$ It may be that this indirectly results in the development of autonomy in some, but only because they are left alone and people left alone often strive to improve themselves.

${ }^{31}$ In this way, this thin CDL has antecedents in the writings of Baruch Spinoza, Pierre Bayle, and John Locke, as well as Mill. It also bares a resemblance to Kukathas's recent view (in 2003).

${ }^{32}$ By contrast, an autonomist CDL_-including that of early Rawls-requires respect for persons as autonomous agents, whether they are autonomous, want to be autonomous, or would be better off being autonomous. Even Rawls's PL seems to require respect for persons not as they are but as something more idealized-as free and equal, whether they are, whether they want to be, or whether they are better off that way. The CDL discussed in this section is, I think, "thinner" than both the autonomist CDL and PL precisely because its concern is with harm to persons as they are rather than persons in some idealized way. While its true that what counts as harm-i.e., what counts as wrongful and a setback to interests - is controversial, harm is the only element of this view that would be controversial whereas the other views also require defense of their idealizations of persons. The idea for this footnote was prompted by discussion with Stephen Herman; I appreciate that discussion.
} 
To be clear, this view does not deny autonomy is a value, but recognizes that it is not valued by or important for all. It is consistent with this to insist that autonomy has great intrinsic and instrumental value. However, that claim does not entail that all should be autonomous.

Certainly, some who are not autonomous and do not value autonomy probably should — they may well live better lives if they were autonomous. But this is a contingent claim and surely there are some for whom living autonomously means living less well than living non-autonomouslywhether because they fare better in a group with others where no one is autonomous or because they themselves are not capable of meeting the challenges that autonomy raises. Kukathas gives us an example of the former-Australian Aborigines who "follow up The Dreaming" rather than determine for themselves what they should pursue (102, quoting Maddock; see also Lomasky 4247). Examples of the second sort, for better or worse, live all around us. These are individuals who despite extensive attempts to educate them, make life mistake after life mistake. They take out the wrong sort of mortgages, have children they cannot give appropriate attention to, spend money on frivolities when necessities are lacking, etc. Such individuals are striving (perhaps) to "make it on their own" but fail time and time again. Some will say that society failed to educate them well enough. Its unclear, though, why we should not instead think society failed them by trying to educate them so as to be autonomous. ${ }^{33}$ Perhaps a different sort of education-one wherein they learned to abide by simple rules or mimic someone else-would have been better suited. Admittedly, this is conjecture, but conjecture is all we have here. ${ }^{34}$

The original Rawlsian CDL may seek to make people morally autonomous. PL explicitly seeks only to guarantee political autonomy, satisfied that people know they can vote and move (etc.) as they wish (this presumably provides respect for persons). Guaranteeing political autonomy, though, is likely to cause spillover effects wherein people become autonomous in more areas of their lives than PL ostensibly requires (it is also based on the idea that people are to be respected as free and equal as noted in footnote 32). The thin CDL discussed here does not promote even the more minimal form of autonomy. Admittedly, there is a paradox in that if citizens are not

\footnotetext{
${ }^{33}$ I here switch from autonomy as a capacity to autonomy as a goal (or success term). I do not think this is a problem as it is the fact that such people continually fail to succeed when acting on their capacity to act autonomously that suggests they do not sufficiently have that capacity.

${ }^{34}$ I should add that what I say in this paragraph is not intended as a value judgment ranking those without autonomy lower than those with. The judgment is only that some can live better lives without living autonomously than that they would live if required to be autonomous.
} 
autonomous, they can't (autonomously) decide if they want to be. This means that this form of liberalism cannot guarantee that individuals will pursue the lives they would pursue autonomously. This, in turn, means that their families or communities may retain a large degree of control over them. How can this be permissible? How can we sit back and allow families or religious or cultural groups to indoctrinate children such that said children would never choose to leave them or join some other group? ${ }^{35}$ Simply put, we must allow that people are necessarily socialized by others and if an individual is socialized in such a way that she will not consider leaving her family or group, we must recognize that this is something important about her as the person she has become and we would fail to show her respect if we insisted that there is something wrong with her because we think she cannot possibly be consensually in her group (cf. Meyers, xi). We must accept that she does consent. We may, of course, condemn and seek to change the socialization process, ${ }^{36}$ but to insist that the individual would not consent if she weren't who she is is to engage in a non sequitar. More to the point here, forcing her to become autonomous would be harming her as she is by forcing her to live against her conscience; it would be to discount and set back the interests she currently has without concern for what she wants. This is not a way to show her respect; respecting persons is respecting them as they are.

The thin CDL discussed here tolerates more diversity than autonomist CDL or PL because it accepts that if individuals are content with (acquiesce to) the lives they lead, ${ }^{37}$ they should be tolerated as the people they are. They should be free to act in accord with their conscience. Both the individual who has her autonomy infringed against her will and the individual who has his autonomy promoted against his will have their interests set back. This thin CDL opposes both. ${ }^{38}$ If, though, an individual opposes the way they are (presumably being forced to be) living their

\footnotetext{
${ }^{35}$ Remainder of paragraph adapted from my 2007, 503-504.

${ }^{36}$ I doubt we should seek to change the world such that are all are socialized to be autonomous- for the reasons just discussed.

${ }^{37}$ While Rawls might oppose this in other arenas, he tells us that "traditional gendered division of labor within families ... adopted by people on the basis of their religion" could be "fully voluntary" (1999, 599). Surely, this is nothing more than acquiescence.

${ }^{38}$ The issue is somewhat more complicated because of the status of children. On this account, parents can raise their children as they wish so long as they do not harm them. Raising a child to be autonomous may have value, but absent an argument that it is necessarily wrongful and necessarily sets back the interests of every child to fail to do so, a policy of interference (educationally or otherwise) to make children autonomous will not be accepted. Of course, in particular cases, a parent will be wronging their child by not raising her to be autonomous. But, per the discussion above, it may also be that in particular cases, a parent wrongs a child by raising him to be autonomous.
} 
own life, they would be expressing autonomy and that should be protected - in such cases interference (by the state or otherwise) is permissible, in accord with the harm principle. There, toleration rightfully ends. Either way, people can live according to their conscience. This is interestingly in agreement with PL. "Respecting others as persons and as citizens involves allowing them to non-coercively decide their values and (within limits of justice) act on their chosen ways of life" (Freeman, 233). As already indicated, we might doubt that PL lives up to that promise.

Let's take stock one last time before concluding. CDL has independently defended principles indicating when limits of toleration have been transgressed. The thin CDL discussed in this section is no exception. Its principles, though, require much more toleration than the autonomist CDL discussed earlier. Indeed, it manages to require more toleration than PL as it does not insist on political autonomy or on treating people as free and equal (and has no bargaining table from which to exclude the unreasonable).

\section{Conclusion}

The view just discussed may not properly be a CDL since it doesn't tell people what to do in many areas of their lives (other than telling them that they ought not interfere with others). Indeed, some think it is the "distinctive and defining feature of political liberalism" that it not "invoke any particular conception of the good life" (Gutmann, 560) so this view may seem like a PL. Still, it is not a PL if PL only endorses values derived from an overlapping consensuswhich, as we saw, Larmore denies. The core value of this CDL is the freedom from harm that is entailed by the respect given persons as the persons they are rather than the persons they could be if fully autonomous or otherwise perfected - and this is not a value derived from an overlapping consensus. It is a conception "of what is of value in human life" 39 taken broadly (though it offers no means of specifying how individual humans should live, leaving that to individuals, families, and communities, it provides a normative limit to what must be tolerated). Having such a value is, we are told, part of what it is to be a CDL. If, though, Larmore is right that even PL has a core value - respect for persons (presumably in an idealized form as being

\footnotetext{
${ }^{39}$ Rawls 1993, 13, quoted in section I above.
} 
free and equal) - that is not derived from an overlapping consensus, then reliance on overlapping consensus to defend its core value is not a distinguishing feature of PL. If this is right, then the thin CDL discussed here may well be a form of PL. If that is the case, its insistence on respect for persons as they are rather than as they could be differentiates at least from Rawls's PL.

Whether the thin CDL discussed here is a form of PL or of CDL is not of much importance. We might call it substantive liberalism (SL) as it relies on a substantive defense of its core valuefreedom from harm - and recognizes that value may be controversial. That value must be defended on objective grounds that all should be able to accept, but such acceptance is not essential to SL. SL does not insist that people are unreasonable (though they may be) if they reject it, but does not allow them to interfere with the state policy of toleration it requires (nor does SL justify any other state interference in their lives).

We conclude by briefly considering the paradox of liberalism. We can put the paradox simply: Persons living in a liberal state who are militantly anti-liberal should either be tolerated or not. If tolerated, non-liberalism - which limits toleration - is allowed. If not tolerated, the state is nonliberal. The paradox is supposedly embarrassing to liberalism since it is a commitment to toleration, which is curtailed either way. ${ }^{40}$ The paradox supposedly shows that the range of toleration - and hence liberty - that liberalism allows is not so extensive. Can a liberal state outlaw those seeking to end its rule?

How would each of the three views discussed answer this question? Consider a fictitious aboriginal group in the U.S. whose members do not value autonomy but who act in accord with the dreams of their leader, ${ }^{41}$ and who believe that doing such is necessary for salvation. To embellish the case further, imagine that the dreams require that all blue-eyed people must wait to eat until all of the brown-eyed people have eaten. This is the only way the blue-eyed are treated as second class, but it remains deeply ingrained in the group - accepted by brown- and blue-eyed people alike. The group members realize they can't enforce this rule on the rest of us, but they would if they could. They sometimes try political campaigns to pass a law making violation of

\footnotetext{
40 This description adapted from my 2013.

${ }^{41}$ The group as specified is fictitious but modeled on Australian Aborigines mentioned above.
} 
the requirement a criminal offense (out of concern for the rest of us - they want us all to go to heaven and believe this requires abidance with this rule).

The three views - autonomist CDL, PL, and SL — are united in that they would not tolerate the passage of a law requiring abidance with the rule just discussed since it would impose a decidedly non-liberal requirement on unwilling agents. The autonomist CDL would not even tolerate an abidance requirement for those within the group since it would infringe their moral autonomy (autonomous choice to abide by the rule would be tolerated). The PL might tolerate the abidance requirement within the group if its members retained political autonomy and the democratic system was not otherwise hindered. The SL would tolerate the abidance requirement within the group so long as it involves no harm to others and all who are in the group are in it in accord with their own consciences so that they have no interests wrongly set back. The SL is not concerned to promote moral or political autonomy of any agent unless that agent has an actual interest in such autonomy - in which case, the interference permitted is the prevention of a harm that is the hindering of the relevant form of autonomy.

So, the blunt question: what should the liberal say to those seeking to end its rule? The CDL clearly has no qualms using state force to maintain the liberal regime. Unsurprisingly, though, the PL says the same thing. In that view,

Democratic citizens and government officials ... can always argue about and contest the laws and the correct understanding of constitutional provisions, and even the alternative liberal conceptions of justice that are appealed to in public reason to justify laws. What they cannot do ... is contest liberalism itself, or provide reasons incompatible with a liberal constitution (Freeman, 241).

The CDL will protect the liberal regime in the name of its underlying value - in the case of the autonomist CDL, that is autonomy and in the case of SL, its freedom from harm. The former endorses a particular conception of the good life that some might reject, but the latter does not; it requires only that all non-harmful behaviors be tolerated. According to the SL, the state justifiably interferes to prevent harm — and this includes preventing an overthrow of the regime since such an overthrow would likely itself include harms and would leave a path for further harms (after all, the raison d'etre of the regime is harm prevention). 
All three liberal theories we've discussed would respond to the paradox of liberalism by insisting on maintaining the liberal regime. The two CDLs (autonomism and SL) do this in the name of their underlying values; the PL does much the same-with its underlying value being political autonomy or respect for persons. This is no embarrassment for liberals; it is merely commitment to liberalism. Importantly, though, the theories we've discussed have different limits of toleration within that constraint. SL tolerates more than PL. PL likely tolerates more than the autonomist CDL. The question that cannot be answered here is simply "which view, with its limits on toleration, is the best view for a liberal to adopt?" 
Andrew Jason Cohen "Liberalism \& Toleration," for Cambridge Companion to Liberalism

\section{Works Cited}

Barry, Brian 2001. Culture and Equality. Cambridge: Harvard University Press.

Bayle, Pierre 1688. A Philosophical Commentary on These Words of the Gospel, Luke 14:23, 'Compel Them to Come In, That My House May Be Full.' Indianapolis: Liberty Fund, 2005.

Bratman, Michael. Faces of Intention. Cambridge: Cambridge University Press, 1999.

Cohen, Andrew Jason. "Toleration.” The International Encyclopedia of Ethics. Ed. LaFollette, Hugh. Oxford: Blackwell, 2013.

-----. "What the Liberal State Should Tolerate Within Its Borders." Canadian Journal of Philosophy Volume 37, 2007 (479-513).

-----. "What Toleration Is.” Ethics Volume 115, 2004 (68-95).

Cohen, Joshua. "Truth and Public Reason." Philosophy \& Public Affairs Volume 37 No. 1, $2009(2-42)$.

D’Agostino, Fred. Free Public Reason. New York: Oxford University Press, 1996.

Davis, Gordon and Blain Neufeld. "Political Liberalism, Civic Education, and Educational Choice." Social Theory and Practice Volume 33, 2007 (47-74).

Feinberg, Joel. Harm to Others. New York: Oxford University Press, 1984.

Freeman, Samuel. "Public Reason and Political Justification." Justice and the Social Contract: Essays on Rawlsian Political Philosophy. Oxford: Oxford University Press, 2007 (215256).

Friedman, Marilyn. "John Rawls and the Political Coercion of Unreasonable People." The Idea of A Political Liberalism: Essays on Rawls. Ed. Victoria Davion and Clark Wolf. Lanham: Rowman and Littlefield, 2000 (16-33).

Gaus, Gerald. The Order of Public Reason. New York: Cambridge University Press, 2011.

Gilbert, Margaret. Sociality and Responsibility. Lanham, MD: Rowman and Littlefield, 2000.

Gutmann, Amy. "Civic Education and Social Diversity," Ethics, Volume 105, No. 3, 1985: 557 579.

Hampton, Jean. "Should Political Philosophy Be Done without Metaphysics?" Ethics Volume 99, 1989 (791-814). 
Andrew Jason Cohen "Liberalism \& Toleration," for Cambridge Companion to Liberalism

Hartley, Christie and Lori Watson. "Feminism, Religion, and Shared Reasons: A Defense of Exclusive Punlic Reason." Law and Philosophy Volume 28, 2009 (493-536).

Kukathas, Chandran. The Liberal Archipelago. New York, NY: Oxford University Press, 2003.

Larmore, Charles. "The Moral Basis of Political Liberalism." The Journal of Philosophy Volume 96 No. 12, 1999 (599-625).

Lomasky, Loren. Persons, Rights, and the Moral Community. NY: Oxford University Press, 1987.

Mill, John Stuart. On Liberty. Ed. Elizabeth Rapaport. Indianapolis: Hackett Publishing, 1978 (originally 1959).

Mills, Claudia. "Not a Mere Modus Vivendi': The Bases for Allegiance to the Just State." The Idea of A Political Liberalism: Essays on Rawls. Ed. Victoria Davion and Clark Wolf. Lanham: Rowman and Littlefield, 2000 (190-203)

Meyers, D. T. Self, Society and Personal Choice. New York: Columbia University Press, 1989.

Nagel, Thomas. "Moral Conflict and Political Legitimacy." Philosophy and Public Affairs Volume 16 No. 3, 1987 (214-240).

Rawls, John. "The Idea of Public Reason Revisited.” Collected Papers. Ed. Samuel Freeman. Cambridge: Harvard University Press, 1999 (573-615).

-----. Political Liberalism. New York: Columbia University Press, 1993.

-----. A Theory of Justice. Cambridge: Harvard University Press, 1971.

Scalet, Steve. "Legitimacy, Confrontation Respect, and the Bind of Freestanding Liberalism." Journal of Social Philosophy Volume 41 No. 1, 2010 (92-111).

Tan, Kok-Chor. Toleration, Diversity, and Global Justice. University Park: Pennsylvania State University Press, 2000.

Wenar, Leif. "Political Liberalism: An Internal Critique." Ethics Volume 106, 1995 (32-62). 